\title{
Erratum to: Self-Learning Optimal Control of Nonlinear Systems
}

\section{Erratum to:}

Q. Wei et al., Self-Learning Optimal Control of Nonlinear Systems, Studies in Systems, Decision and Control 103, https://doi.org/10.1007/978-981-10-4080-1

In the original version of the book, the Copyright comment "Not for sale outside the Mainland of China (Not for sale in Hong Kong SAR, Macau SAR, and Taiwan, and all countries, except the Mainland of China)" has been updated as "The printed edition is not for sale in China Mainland. Customers from China Mainland please order the print book from Science Press, Beijing, China" in Frontmatter. 